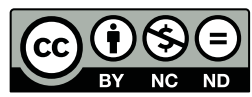

Estudos Teológicos foi licenciado com uma Licença Creative Commons Atribuição - NãoComercial - SemDerivados 3.0 Não Adaptada

http://dx.doi.org/10.22351/et.v.57i2.2926

\title{
UM SÍMBOLO DA DIFERENÇA: PERTENÇA, VIOLÊNCIA E RESISTÊNCIA NA CIRCUNCISÃO JUDAICA ${ }^{1}$
}

\author{
A symbol of difference: belonging, violence, \\ and resistance in Jewish circumcision
}

\section{Willibaldo Ruppenthal Neto ${ }^{2}$ Renan Frighetto ${ }^{3}$}

\begin{abstract}
Resumo: O presente artigo visa analisar a circuncisão como elemento constitutivo da identidade judaica enquanto símbolo da diferença. A partir dos dois textos bíblicos instituidores da circuncisão, nos relatos referentes a Abraão e Moisés, será demonstrada a circuncisão como construção doutrinária a partir da sua justificação enquanto violência necessária, que marca a pertença à cultura judaica e que, em determinadas condições, serve como mecanismo de resistência. Assim, serão evidenciadas suas relações com o pertencimento familiar, com a prática sacrificial e mesmo com a resistência política, seja na sua prática em situações de proibição ou mesmo na sua negação em situações de imposição. Depois de apresentados esses três aspectos da circuncisão, embasados em textos bíblicos e na história do judaísmo, evidenciar-se-á a relação dos mesmos com a constituição da diferença, demonstrando que a circuncisão serve ao mesmo tempo como elemento identitário, unindo e integrando os judeus, e excludente, separando-os e diferenciando-os dos demais.
\end{abstract}

Palavras-chave: Circuncisão. Judaísmo. Identidade.

Abstract: This article aims to analyze the circumcision as a constitutive element in Jewish identity as symbol of difference. From both biblical texts that institute circumcision, in the accounts about Abraham and Moses, will be demonstrated the circumcision as a doctrinal construction from the justification as a necessary violence, marking the belonging to Jewish culture, and even, in certain circumstances, working as a resistance

1 Este artigo foi recebido em 16 de janeiro de 2017 e aprovado em 14 de abril de 2017 com base nas avaliações dos pareceristas ad hoc.

2 Mestrando do Programa de Pós-Graduação em História da Universidade Federal do Paraná (UFPR), em Curitiba/PR, Brasil. Graduado em História pela UFPR e bacharel em Teologia pelas Faculdades Batista do Paraná (FABAPAR). Membro discente do NEMED/UFPR. Bolsista CNPq. Contato: willibaldoneto@ hotmail.com

3 Doutor em História Antiga pela Universidade de Salamanca (1996), na Espanha; mestre em História Antiga e Medieval pela Universidade Federal do Rio de Janeiro (1990); professor associado da Universidade Federal do Paraná, em Curitiba/PR, Brasil - Departamento de História. Pesquisador 1D CNPq; pesquisador do NEMED/UFPR. Contato: rfrighetto@hotmail.com 
mechanism. Therefore, will be shown its relations to the family belonging, the sacrificial practice, and even with the political resistance, either in its practice in situations of prohibition or even in its denial in situations of imposition. After presenting these three aspects of circumcision, based on biblical texts and the history of Judaism, will be shown the relationship between them and the constitution of difference, demonstrating that circumcision serves both as an identity element, uniting and integrating the Jews, and an element of exclusion, separating and differentiating them from the others.

Keywords: Circumcision. Judaism. Identity.

\section{Introdução}

Quando se pensa na constituição da identidade judaica na antiguidade, a prática da circuncisão logo vem à mente. A circuncisão era, e ainda é, uma marca de distinção, de demarcação cultural, de afirmação identitária, e também, claro, de obrigação por parte dos judeus. Acontece, porém, que os judeus não eram os únicos a praticar a circuncisão no mundo antigo, uma vez que essa prática estava presente entre os sacerdotes egípcios ${ }^{4}$ e ainda outros $\operatorname{povos}^{5}$, de modo que não foi, portanto, propriamente uma invenção judaica. Mesmo assim, porém, a prática da circuncisão remete quase naturalmente ao povo judeu pela importância dada a essa tanto na relação com sua história religiosa ${ }^{6}$ como por ser uma forma de afirmação da identidade judaica.

A identidade judaica constituiu-se historicamente principalmente mediante a construção de uma relação entre história e crença religiosa. Assim, a história da formação do povo judeu, em seu próprio discurso, está completamente relacionada à sua história religiosa, uma vez que o patriarca do povo judeu, Abraão, é convocado por Deus não somente para se deslocar de sua terra para a Judeia, como ainda para ser o patriarca de uma grande nação planejada pelo próprio Deus. Desta forma, há, segundo o relato bíblico, um vínculo fundamental entre o povo judeu e o seu Deus, que escolhe esse povo a fim de direcionar sua história. A instituição da circuncisão se dá, dentro desse contexto, como a moldura da aliança entre Deus e Abraão ${ }^{7}$, na qual se inserem as promessas do nascimento de Isaque e da bênção referente à descendência de Abraão. ${ }^{8}$

A circuncisão, portanto, é biblicamente apontada como o símbolo do vínculo entre os judeus e seu Deus, enquanto uma expressão da aliança com Deus, que cada homem judeu carrega em seu próprio corpo, como representante da descendência de

4 Cf. Heródoto, Hist., 2.104.1-3 (HERODOTUS, 1975, p. 391-393).

5 No Antigo Testamento, cf. Jz 14.3; 15.18; 1Sm 14.6; 17.26,36; 18.27; 31.4; 2Sm 1.20; 3.14; $1 \mathrm{Cr} 10.4$. Outro relato importante é Epístola de Barnabé, 9.6.

6 A circuncisão é utilizada como símbolo da obediência a Deus na linguagem dos profetas, a exemplo de Jeremias. Além do "coração incircunciso", presente em Jeremias 9.25-26 e Levítico 26 (BERNAT, David A. Sign of the Covenant: Circumcision in the Priestly Tradition. Atlanta: Society of Biblical Literature, 2009. p. 97-114), há as imagens das “árvores frutíferas incircuncisas” em Levítico 19 (BERNAT, 2009, p. 91-96), e dos "lábios incircuncisos” de Moisés em Êxodo 6 (BERNAT, 2009, p. 83-89).

7 Gn 17.9-14, 23-27.

8 Gn $17.15-22$. 
Abraão, prometida por Deus e realizada no povo judeu. Trata-se de uma marca da aliança, que relaciona e conecta todo um povo com seu Deus, segundo o relato bíblico. É, verdadeiramente, como indicado por Gerhard von Rad, "uma questão do seu [de Israel] testemunho de Yahweh e seu direcionamento da história" . Ao mesmo tempo, a circuncisão possui significações culturais que vão para além de seu aspecto teológico, de modo que Howard Eilberg-Schwartz ${ }^{10}$, Lawrence Hoffman ${ }^{11}$ e William H. Propp ${ }^{12}$, por exemplo, mediante uma interpretação histórico-antropológica, puderam indicar sua origem em ritos de fertilidade, tendo sido transformada em um símbolo da aliança divina pela tradição sacerdotal judaica, presente dentro da composição bíblica. ${ }^{13}$

Historicamente, portanto, a circuncisão vai além de um símbolo da aliança, se apresentando, na relação homem-homem, como um mecanismo de corte, estabelecendo uma pertença, justificando uma violência e configurando-se como uma forma de resistência, como será demonstrado. Neste texto, portanto, se apresentará um estudo a respeito da relação da circuncisão com a estrutura familiar (como pertença), com o sangue derramado (como violência) e com seu aspecto de decisão (como resistência). Ao final se evidenciará que os três elementos são constitutivos de diferença, ao mesmo tempo estabelecendo uma identidade e diferenciando seus integrantes dos outros. Esses elementos, porém, não se deram somente a partir do conflito com o cristianismo, como se poderia pensar, mesmo que este tenha sido particularmente importante ${ }^{14}$, mas já estão presentes na própria tradição da Bíblia Hebraica. Sendo assim, os principais textos na instituição da circuncisão (como Gênesis 17 e Êxodo 4) serão analisados pormenorizadamente, a fim de se extrair dos mesmos os aspectos sobre os quais a fundamentação dessa prática se apresenta.

\section{Circuncisão, família e pertença}

Apesar da circuncisão se estabelecer como um vínculo de paternidade, principalmente pela figura do "pai Abraão", a relação entre circuncisão e descendência vai além da continuidade da linhagem abraâmica, tendo como base de apoio o sistema familiar paternalista. De fato, era comum na Antiguidade uma centralização do poder

9 VON RAD, Gerhard. Genesis: A Commentary. Louisville: Westminster John Knox, 1972. p. 201.

${ }^{10}$ EILBERG-SCHWARTZ, Howard. The Savage in Judaism: An Anthropology of Israelite Religion and Ancient Judaism. Bloomington: Indiana University Press, 1990. p. 141-176.

${ }^{11}$ HOFFMAN, Lawrence A. Covenant of Blood: Circumcision and Gender in Rabbinic Judaism. Chicago; London: University of Chicago Press, 1996. p. 27-48.

12 PROPP, William H. The Origins of Infant Circumcision in Israel. Hebrew Annual Review, v. 11, p. 355$370,1987$.

${ }_{13}$ Particularmente importante, no que diz respeito ao presente texto, é o livro Sign of the Covenant, de David A. BERNAT (2009), que buscou estudar a circuncisão dentro da tradição sacerdotal, ou seja, a partir da fonte P.

${ }^{14}$ Tal como bem demonstrado por Maren R. Niehoff (NIEHOFF, Maren R. Circumcision as a Marker of Identity: Philo, Origen and the Rabbis on Gen 17:1-14. Jewish Studies Quarterly, v. 10, p. 89-123, 2003), o conflito com o cristianismo resultou em uma transformação na relação dos judeus com a circuncisão, assim como lhe deu uma nova significação, como diferenciação para com o cristianismo. 
familiar na figura paterna. Esse poder também era comumente vinculado ao controle dos corpos, de modo que em muitas culturas o pai tinha direito sobre os corpos de seus familiares, que lhe são sujeitos. Assim, no caso romano, por exemplo, o pater familias tinha poder de vida e morte sobre seus familiares, poder esse outorgado pela própria legislação romana. ${ }^{15}$ No caso judaico, porém, a relação entre poder, controle e corpo era mais profunda, de modo que o vínculo familiar não apenas se expressava, mas realmente se fundamentava no controle familiar dos corpos, apesar de limitada em comparação ao caso romano.

A circuncisão, portanto, servia tanto como uma expressão do poder dos pais sobre os filhos, imposto pela sujeição do corpo a um corte não voluntário, como ainda enquanto uma inserção do filho à família, servindo como vínculo de pertencimento. Somente se compreende a profundidade dessa relação quando se percebe que a família, no contexto judaico, se apresentava de forma diferente da tradicional aferição de pertencimento sanguíneo, expressando-se enquanto pertencimento corpóreo: os membros de uma família não são "do mesmo sangue", mas são "da mesma carne", ou ainda "do mesmo corpo"16. Essa ideia é ainda mais explicitada na compreensão da palavra hebraica $b \bar{a} s \bar{a} r($ (

Apesar da palavra $b \bar{a} s \bar{a} r$ ser tradicionalmente traduzida como "carne", uma vez que de fato é a palavra utilizada para aferições relativas a animais carneados ${ }^{18}$, é a

15 O pater familias tinha o direito não somente de rejeitar seu filho e abandoná-lo à morte, como ainda de vendê-lo, cf. Plutarco, Sólon 13; Dionísio de Halicarnasso, Antiquitates Romanae 2.27.1-3; Gaio, Institutiones 1.117, 6.79; Ulpiano, Fragmento 10.1; Tito Lívio, Ab Urbe Condita 41.8. Evidentemente, portanto, o filho era tido como uma propriedade do pai, apesar da Lei das Doze Tábuas estabelecer um limite de somente três vezes que um pai poderia vender o seu filho e tomá-lo de volta, ficando o filho livre após a terceira venda: "Si pater filium ter venum duit, filius a patre liber esto" (Tábua 4.2; Ulpiano, Fragmento 10.1). É possível, porém, que essa lei se referisse à prostituição dos filhos, e não sua venda, cf. STOOP, Ben. The Sins of their Fathers: Si pater filium ter venum duit. Revue internationale des droits de l'antiquité, n. 42, p. 331-392, 1995. De toda forma, a lei evidencia o poder paterno sobre os corpos de seus filhos.

${ }^{16}$ Hans Walter Wolff destaca essa diferenciação do hebraico com o acádico, que utiliza o sangue para designar o parentesco (“de sangue”). Cf. WOLFF, Hans Walter. Antropologia do Antigo Testamento. São Paulo: Hagnos, 2008. p. 62, nota 72.

${ }^{17}$ Sobre a palavra hebraica $b \bar{a} s \bar{a} r$, cf. WOLFF, 2008, p. 57-65; BURTON, Ernest D. Spirit, Soul and Flesh:

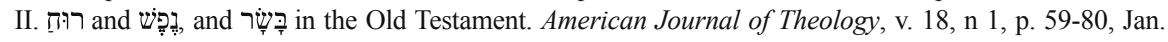
1914; OSWALT, John N. Bâsar. In: HARRIS, R. Laird; ARCHER JR., Gleason L.; WALTKE, Bruce K. Dicionário Internacional de teologia do Antigo Testamento. São Paulo: Vida Nova, 1998. p. 226-228; BROWN, F.; DRIVER, S. R.; BRIGGS, C. A. (eds.). A Hebrew and English Lexicon of the Old Testament: with an appendix containing the biblical aramaic. Based on the Lexicon of William Genesius as translated by Edward Robinson. Boston; New York: Houghton Mifflin Company, 1907. p. 142; RUPPENTHAL NETO, Willibaldo. O ser humano necessitado: as implicações do conceito de nefesh nas ideias de homem, vida e morte na antropologia do Antigo Testamento. Trabalho de Conclusão de Curso (Teologia) - Faculdades Batista do Paraná, Curitiba/PR, 2015. p. 8-10; RUPPENTHAL NETO, Willibaldo. A vida humana no Antigo Testamento. Protestantismo em Revista, São Leopoldo, v. 42, p. 172-185, set./dez. 2016. p. 173-175.

${ }_{18}$ Cf. Lv 4.11; 7.15-21; Nm 19.5; Is 44.16 etc. Gerleman indica que a palavra $b \bar{a} s \bar{a} r$ aparece 61 vezes no livro de Levítico (WOLFF, 2008, p. 58, nota 65), o que é em boa medida resultante do fato de que "na maioria das vezes, fala-se da carne dos animais de sacrifício em prescrições rituais” (WOLFF, 2008, p. 58). 
palavra hebraica para se referir ainda à carne humana ${ }^{19}$, assim como seu corpo ${ }^{20}$, carregando o sentido de efemeridade ${ }^{21}$. No entanto, além desse aspecto material, $b \bar{a} s \bar{a} r$ possui um recorrente uso em sentido jurídico, consistindo, segundo Hans Walter Wolff, no "termo jurídico para designar quem pertence à família"22. Dessa forma, os irmãos de José podem falar dele que "é nosso irmão e nossa carne $[b \bar{a} s \bar{a} r]$ "23, e ainda se tem expresso que quando "deixa um homem pai e mãe, e se une à sua mulher", os dois se tornam "uma só carne [bāsār]"24.

A criação de uma nova família, portanto, como resultado da união entre um homem e uma mulher e desvinculação de suas respectivas famílias, é entendida como o surgimento de uma nova "comunidade de vida", expressa em uma unidade de um "corpo comum" "25. Apesar do vínculo familiar, de parentes "de sangue" - ou melhor, "de corpo" -, ser extremamente valorizado, se faz necessário o entendimento de que a ideia judaica de família, de $b \bar{a} s \bar{a} r$, se estendia não somente aos parentes mais distantes, como ainda a todo o clã (mishpaha $)^{26}$, e mesmo a todos que estivessem sujeitos ao poder do patriarca, incluindo seus servos e escravos, que fazem parte de sua "casa", sua bayit (בַּית (27 . Assim, bayit pode expressar tanto a descendência de alguém - como a bayit de Abraão ${ }^{28}$ ou a bayit de Davi ${ }^{29}$-, como ainda aqueles que vivem sob o controle de um patriarca. ${ }^{30}$ Dessa forma, as ideias judaicas de "casa" e "família" eram expressas na palavra hebraica bayit, que incluía, segundo Erhard Gerstenberger, "parentes, escravos ou escravas e visitas permanentes, que conviviam na casa e participavam do trabalho cotidiano"31.

É interessante notar que apesar de $b \bar{a} s \bar{a} r$ ter tanto o sentido de corpo quanto de família, somente expressa um único órgão ou membro do corpo humano quando vêm a designar o membro viril, o pênis. ${ }^{32}$ Assim, em Gênesis 17.11, é determinado por Deus a Abraão o seguinte: "Circuncidareis a carne $[b \bar{a} s \bar{a} r]$ do vosso prepúcio; será isso por

19 A palavra $b \bar{a} s \bar{a} r$ aparece em alguns textos como complementar/oposta aos ossos, dando o sentido de “carne". Cf. Gn 2.21; Jó 2.5; Sl 102.5. Em outro texto complementa o corpo para além dos ossos e da pele (Lm 3.4), em outro somam-se os músculos (Jó 10.11), e em outro ainda a respiração (Ez 37.5s).

${ }^{20}$ Cf. 1Rs 21.27; Pv 4.22; Sl 38.4; 119.120.

${ }^{21}$ Cf. WOLFF, 2008, p. 64-65.

${ }^{22}$ WOLFF, 2008, p. 62. Também a expressão "meus ossos e minha carne" se apresenta neste sentido. Cf. Gn 2.23; 29.14; Jz 9.2; $2 \mathrm{Sm} 5.1 ; 19.13 \mathrm{~s}$.

${ }^{23}$ Gn 37.27 (ARA).

${ }^{24}$ Gn 2.24 (ARA).

${ }^{25}$ Cf. WOLFF, 2008, p. 61.

${ }^{26}$ Cf. Lv 25.49.

${ }^{27}$ Sobre a palavra hebraica bayit, cf. GOLDBERG, Louis. Bayit. In: HARRIS; ARCHER JR.; WALTKE (eds.), 1998, p. 174-176; MORAES, Reginaldo Pereira de. A família no Antigo Oriente Próximo: uma descrição veterotestamentária. Hermenêtica, v. 11, n. 1, p. 65-79, 2011. p. 66-67.

${ }^{28} \mathrm{Cf}$. Gn 18.19.

${ }^{29}$ Cf. $2 \mathrm{Sm} 7.11$

${ }^{30}$ MORAES, 2011, p. 66. Cf. Gn 35.2.

${ }^{31}$ GERSTENBERGER, Erhard. Casa e casamento no Antigo Testamento. Estudos Teológicos, v. 42, n. 1, p. 81-89, 2002. p. 83-84.

32 WOLFF, 2008, p. 59. Cf. Lv 15.2s, 7,19; Ez 16.26; 23.20; GLICK, Leonard B. The Life of the Flesh is in the Blood: The Meaning of Bloodshed in Ritual Circumcision. In: DENNISTON, George C. et al. (ed.). 
sinal de aliança entre mim e vós". Essa aliança estabelecida entre Deus e Abraão não se limita, porém, ao próprio corpo de Abraão, mas se estende a toda a sua bayit:

O que tem oito dias será circuncidado entre vós, todo macho nas vossas gerações, tanto o escravo nascido em casa [bayit] como o comprado a qualquer estrangeiro, que não for da tua estirpe. Com efeito, será circuncidado o nascido em tua casa e o comprado por teu dinheiro; a minha aliança estará na vossa carne $[b \bar{a} s \bar{a} r]$ e será aliança perpétua ${ }^{33}$.

É evidente, aqui, a ideia do poder do patriarca sobre toda a sua "casa", ou seja, sobre seus filhos e seus escravos. Esse poder é decorrente de uma fonte de autoridade - o nascimento em sua casa, ou a compra por seu dinheiro. Em ambos os casos, os sujeitos de sua bayit the são como uma posse, de modo que são incluídos enquanto sua própria $b \bar{a} s \bar{a} r$. A $b \bar{a} s \bar{a} r$ marcada como aliança para com Deus ${ }^{34}$, portanto, não se limita ao corpo do patriarca (neste caso Abraão), mas inclui ainda os corpos daqueles que fazem parte de sua bayit.

Não devemos, porém, naturalizar a relação entre corpo/pênis/família presente na cultura judaica antiga, mas antes perceber que a particularidade do membro viril como único caso em que um membro do corpo humano é representado pelo termo hebraico $b \bar{a} s \bar{a} r$ em toda a Bíblia Hebraica não é fruto de originalidade no discurso, mas antes decorrência de condições de possibilidade onde as fronteiras entre corpo, pênis e família não demandaram, mas possibilitaram uma exceção que, antes de ser clarificante, é institucionalizante ${ }^{35}$. Esse discurso instituidor reduz o corpo ao pênis, assim como reduz o povo a Abraão. Deste modo, o pênis não serve somente como representação da integralidade do corpo, mas também - e talvez ainda mais -, de seu pertencimento ao corpo familiar, representado por Abraão.

\section{Circuncisão, sangue e violência}

Apesar de Abraão ser o grande ícone do estabelecimento da circuncisão, Moisés também exerce um papel fundamental na incorporação dessa prática na cultura judaica. ${ }^{36} \mathrm{O}$ texto de Êxodo 4.24-26, que relata o regresso de Moisés ao Egito com

Bodily Integrity and the Politics of Circumcision: Culture, Controversy and Change. New York: Springer, 2006. p. 17-36 [26ss].

${ }^{33}$ Gn 17.12-13. Utilizamos neste artigo a tradução Almeida Revista e Atualizada (ARA).

${ }^{34} \mathrm{Gn} 17.13$.

${ }^{35}$ Um caso de relação entre corpo, pênis e família que não demandou esse uso excepcional é a situação dos juramentos patriarcais. Nos textos de Gênesis 24.2 e 47.29 se fala da demanda pelo patriarca em que seu filho coloque sua mão debaixo de sua "coxa" (järek), um eufemismo para os órgãos genitais masculinos. Assim, se pode também falar que os filhos saíram da jārek de seus pais, cf. Gn 46.26; Êx 1.5; Jz 8.30. Cf. WOLFF, 2008, p. 116, nota 157.

${ }^{36}$ Sigmund Freud, seguindo o relato de Heródoto a respeito da influência egípcia na prática da circuncisão, chega à conclusão de que Moisés foi o responsável pela incorporação deste elemento cultural entre os judeus, assim como de que o próprio Moisés na verdade não era judeu, mas egípcio. Cf. FREUD, Sigmund. Moisés e a religião monoteísta. Tradução Paulo Samuel. Lisboa: Guimarães, 1990. esp. p. 44ss. 
sua família, após ter vivido na região de Midiã, apresenta a circuncisão sob uma aura bastante sombria:

Estando Moisés no caminho, numa estalagem, encontrou-o o SenHor e o quis matar. Então, Zípora tomou uma pedra aguda, cortou o prepúcio de seu filho, lançou-o aos pés ${ }^{37}$ de Moisés e lhe disse: Sem dúvida, tu és para mim esposo sanguinário. Assim, o SENHOR o deixou. Ela disse: Esposo sanguinário, por causa da circuncisão ${ }^{38}$.

Esse aspecto sombrio, porém, termina com um claro destaque ao sangue derramado pela circuncisão - com Zípora chamando Moisés de "sanguinário", "por causa da circuncisão"39 -, que parece servir como meio de aplacar a ira divina: "Assim, o Senhor o deixou". Não é novidade a possibilidade desse texto apontar para um aspecto mágico do sangue da circuncisão. ${ }^{40}$ Por outra perspectiva, porém, pode-se pensar o sangue da circuncisão como modo de oferecer um sacrifício que substitui a morte da criança. Ora, a morte de crianças por rejeição por parte de seus pais era uma prática consideravelmente presente nas culturas antigas, a exemplo dos gregos ${ }^{41}$ e romanos ${ }^{42}$. A cultura judaica, porém, destacou-se pelo cuidado com os filhos e pela ausência dessa prática de rejeição de filhos. ${ }^{43}$ Por que haveria uma demanda da morte do filho?

Uma resposta possível é a suposição de que poderia ser uma forma de sacrifício a Deus. O sacrifício de filhos a divindades é uma prática marcadamente negati-

37 Possivelmente se refere aos órgãos genitais de Moisés. Cf. nota 38.

38 Tradução de Almeida Revista e Atualizada (ARA).

39 Não está claro se a segunda sentença, explicativa, "esposo sanguinário, por causa da circuncisão", é um comentário explicativo ou ainda uma segunda afirmação de Zípora. Pode-se pensar que é uma afirmação de Zípora que rimaria e estaria em conjunto com a primeira afirmação dela. Cf. WILLIS, John T. Yahweh and Moses in conflict: The Role of Exodus 4:24-26 in the Book of Exodus. Bern: Peter Lang, 2010. p. 79.

40 Assim como é possível de se pensar na atitude de Zípora como relacionada ao sangue ritualístico (e não à circuncisão) a fim de expulsar um demônio do deserto que teria atacado Moisés (WILLIS, 2010, p. 79), no Targum Onkelos 4.26 é afirmada a virtude redentiva do sangue da circuncisão, de modo que a própria expressão "esposo sanguinário" seria decorrente do fato de ter sido salvo pelo sangue da circuncisão (WILLIS, 2010, p. 18).

${ }^{41}$ Cf. Demóstenes 39.22 (Contra Boeotus 1); Plutarco, Lyc. 16.1-2; Platão, Politeia 5.460c; Aristóteles, Polit. 7.16.1335b. Como bem indicado por Cynthia Patterson (PATTERSON, Cynthia. 'Not Worth the Rearing': The Causes of Infant Exposure in Ancient Greece. Transactions of the American Philological Association, v. 115, p. 103-123, 1985), a rejeição de crianças na Grécia Antiga poderia ter como causa: a) a criança ter defeitos físicos; b) a criança ser ilegítima; c) haver muitas bocas para alimentar; d) ser uma menina.

${ }^{42}$ Cf. Sêneca, De Ira 1.15.2. Apesar da rejeição de crianças ser aceita pela sociedade romana, "ao mesmo tempo era objeto de tabu" (SCHMITZ, Winfried. Exposure of children. In: BAGNALL, Roger S. et al. The Encyclopedia of Ancient History. New York: Wiley-Blackwell, 2013. p. 2.604-2.605).

${ }^{43}$ Como destacou Paul Veyne, "os gregos e romanos sabiam que uma particularidade dos egípcios, dos germanos e dos judeus consistia em criar todas as suas crianças e não enjeitar nenhuma” (VEYNE, Paul. O Império Romano. In: VEYNE, Paul. (org.). História da Vida Privada. Volume 1: Do Império Romano ao Ano Mil. 9. reimpressão. São Paulo: Companhia das Letras, 1993. p. 23). De fato, não somente os judeus criticaram a rejeição de crianças (cf. Josefo, Cont. Ap., 2.202; Filo, Spec. Leg., 3.110-119), como ainda foram elogiados por não exercerem tal prática (Hecateu de Abdera apud Diodoro Sículo, Bib. Hist. 1.80.6). A respeito da proibição da morte de infantes entre os judeus, cf. Tácito, Hist. 5.5.3. Sobre o caso germano, cf. Tácito, Germ. 19. 
va no Antigo Testamento, sendo rejeitada. Essa rejeição, porém, tem duas exceções consideravelmente claras: Isaque, filho de Abraão, e a filha de Jefté. No caso de Jefté, apesar do relato bíblico não dar uma ênfase negativa ao fato de ter sacrificado sua filha, não somente há uma crítica marcante por parte do judaísmo posterior, como ainda se pode perceber que o caso de Jefté é completamente oposto ao caso de Abraão, em vários sentidos. ${ }^{44} \mathrm{O}$ caso de Abraão, portanto, merece destaque: após Deus lhe pedir o filho em sacrifício, Abraão o conduz a um monte, onde um anjo lhe impede de sacrificá-lo e lhe entrega um cordeiro para ser oferecido no lugar de Isaque. Essa história, conhecida como aquedah, é um elemento importantíssimo no discurso instituidor da história judaica, mas acaba também servindo, no nosso caso, para elucidar o relato de Moisés e a circuncisão de seu filho, que parece ter esse elemento (do sacrifício do filho) como sombra no relato. ${ }^{45}$ Mesmo que não esteja claro a quem Deus "quis matar" - se Moisés ou seu filho ${ }^{46}$-, é o filho de Moisés que precisa ter seu sangue derramado. Em ambos os casos, de Abraão e de Moisés, há uma forma de violência necessária, onde deve haver sangue derramado para apaziguar ou saciar a divindade. ${ }^{47}$ Também parece haver uma relação clara entre esse episódio de Moisés e a Páscoa ${ }^{48}$, quando o sangue de cordeiros foi derramado e aspergido a fim de evitar o derramamento do sangue dos primogênitos. ${ }^{49}$

${ }^{44}$ Cf. REISS, Moshe. Jephthah's Daughter. Jewish Bible Quarterly, v. 37, n. 1, p. 57-63, 2009. p. 61-62.

45 A relação entre circuncisão e sacrifício de filhos está presente no relato do fenício Sanchuniathon, parafraseado por Filo e citado por Eusébio (Praep. Ev., 1.10.33), no qual Kronos se circuncida e a seus partidários logo após matar seu filho. Possivelmente esse mito servia de explicação etiológica para os fenícios, que praticavam a circuncisão (PROPP, 1987, p. 355, nota 1). Cf. Heródoto, Hist., 2.104 (HERODOTUS, 1975, p. 391-393); Aristófanes, Aves, 505-507.

${ }^{46}$ Como bem lembra Lawrence Kaplan, "dos tempos rabínicos ao presente, os estudiosos se dividiram nessa questão, com a maioria favorecendo Moisés, mas uma minoria substancial optando pelo filho, geralmente identificado como Gérson, o primogênito" (KAPLAN, Lawrence. 'And the Lord sought to kill him' (Exod 4:24): yet once again. Hebrew Annual Review, v. 5, p. 65-74, 1981. p. 66). Há ainda quem entenda Eliezer, filho mais novo de Moisés, como o alvo.

47 Assim como há quem indique uma razão para o "ataque divino" em Êxodo 4.24 como resultado da desobediência de Moisés (p. ex. Rashi), ou ainda como resultado de sua falta de aceitação na missão divina (Rashbam), segundo Lawrence Kaplan na verdade o incidente "não serve para nenhum propósito moral ou religioso, mas resulta da inexplicável confusão de identidades que é indicativo da estranheza e irracionalidade que permeia o incidente como um todo" (KAPLAN, 1981, p. 72).

48 William H. PROPP (1987, p. 361) destaca que, assim como em Êxodo 12.44 e 48 é explicitado que somente os circuncidados podem participar da Páscoa, em Josué 5.2-9 há o relato de uma circuncisão em massa das crianças israelitas nascidas no deserto, em Gilgal ("colina dos prepúcios"), a fim de que se celebrasse a Páscoa. No texto Pirkei de-Rabbi Eliezer, é dito que o sangue da circuncisão é colocado nos umbrais das portas (GLICK, 2006, p. 25), tal como o sangue do cordeiro pascal.

49 Cabe um ponto de destaque: no desenvolvimento da tradição judaica, o texto é reinterpretado quanto a quem atentou contra a vida de Moisés (ou seu filho). O Talmude Babilônico (Tratado Nedarim 32a) traz as figuras de Satã e os anjos Af e Hemah como aqueles que atentaram contra a vida de Moisés, enquanto a Septuaginta (LXX) e o Targum Onkelos se referem ao "anjo do Senhor". O Targum de Jerusalém e o Targum de Jônatas, porém, identificam aqui o "Destruidor", também chamado de "anjo da morte", o anjo responsável pela morte dos primogênitos em Êxodo 11. Sobre esse desenvolvimento da tradição, cf. VAILATTI, Carlos Augusto. A Torá e o Mal: um estudo sobre os demônios na Torá. Revista Vértices, n. 12, p. 152-176, 2012. p. 160-166. 
A necessidade da violência, apresentada pelo discurso, parece ter que ser afirmada contra uma incompreensão ou ainda contestação da mesma, que tem em Zípora sua explicitação. A acusação de Zípora contra Moisés como "esposo sanguinário" parece ser o fruto de uma incompreensão em relação à necessidade do derramamento de sangue, de modo que o texto serve como mecanismo de contenção dos discursos contestatórios da prática. A ação é realizada por quem não a compreende, de modo que se institui como prática com poder independente, enquanto elemento necessário. No caso da aquedah, ocorre o contrário: a contestação - da parte do próprio Deus - do sacrifício de crianças fundamenta-se pela substituição através do sacrifício de animais, que o torna desnecessário. No primeiro caso (Moisés), a prática incompreendida (circuncisão por Zípora) dá fundamentação à institucionalização dessa prática, enquanto que, no segundo caso (Abraão), a prática de uma ação institucionalizada (sacrifício de animais) dá fundamentação à contestação de outra prática (sacrifício de crianças). Qual seria, então, a necessidade original que fundamenta a circuncisão e leva Zípora à ação?

Assim como a vida de Isaque é ameaçada pela mão de seu pai, Abraão, a pedido de Deus, uma vida - ou de Moisés ou de seu filho - é ameaçada pela figura do próprio Deus. Em ambos os casos não é somente uma origem divina que fundamenta a necessidade das práticas, mas também a ameaça de morte. É a ameaça de morte que institui o sacrifício, a circuncisão, assim como também a Páscoa e outros ritos. Em todos esses casos há uma demanda de violência por parte do sagrado ${ }^{50}$, em que as práticas ritualísticas se tornam necessárias, uma vez que a violência não pode ser contida, mas somente redirecionada pela substituição. ${ }^{51}$ Assim, o bezerro e o prepúcio substituem a própria criança. Apesar do prepúcio cortado ser parte da própria criança, priva-a da morte; a parte substitui o todo, representando-o. Por esse meio se desfazem e se diluem os discursos contestatórios possíveis que poderiam indicar a circuncisão como uma forma de violência desnecessária. De fato, os gregos, por exemplo, tinham a circuncisão como uma mutilação - algo impróprio e ainda digno de escárnio. ${ }^{52} \mathrm{Na}$ Grécia, apesar da demanda de violência sagrada ter direcionamentos nos quais indi-

${ }^{50}$ René Girard foi um dos principais responsáveis por demonstrar a relação quase indissociável entre violência e sagrado. Sobre o assunto, cf. GIRARD, René. A violência e o sagrado. 3. ed. São Paulo: Paz e Terra, 2008.

51 Segundo René Girard, "só é possível ludibriar a violência fornecendo-lhe uma válvula de escape, algo para devorar" (GIRARD, 2008, p. 15), pois a violência possui força em si mesma, de modo que "a violência não saciada procura e sempre acaba por encontrar uma vítima alternativa” (GIRARD, 2008, p. 13).

52 O prepúcio era tido pelos gregos como uma provisão da natureza (Galeno, De usu partium corporis humani 11.13), de modo que seu corte era tido como prática supersticiosa (Estrabão, Geog., 16.4.5). Mesmo no tempo de Fílon, no século I, tal prática judaica era ridicularizada (Fílon, Leg., 1.1.2). Sobre a imagem do prepúcio e da circuncisão entre gregos e romanos, cf. HODGES, Frederick Mansfield. The Ideal Prepuce in Ancient Greece and Rome: Male Genital Aesthetics and Their Relation to Lipodermos, Circumcision, Foreskin Restoration, and the Kynodesmē. Bulletin of the History of Medicine, v. 75, n. 3, p. 375-405, Fall 2001. 
víduos substituem outros ${ }^{53}$, ou ainda que indivíduos substituem o coletivo ${ }^{54}$, não há, como parece haver no caso judaico, um membro expiatório do corpo. ${ }^{55}$

\section{Circuncisão, decisão e resistência}

Apesar dos gregos num primeiro momento identificarem a circuncisão com os egípcios, uma vez que vieram a conhecer essa prática primeiramente através des$\operatorname{ses}^{56}$, passaram, com o tempo, a associar a circuncisão com os judeus, pelo fato de que, diferente dos egípcios que a tinham como um costume bem particular e restrito - somente os sacerdotes eram circuncidados -, os judeus tinham essa prática como uma obrigação, fazendo parte da lei. A circuncisão, portanto, era primariamente uma obrigação, caráter esse presente na imposição do patriarca a todos que lhe são sujeitos. Isso não implica, também, tristeza por parte dos circuncidados ou do conjunto familiar, até porque a circuncisão, como todo "rito de passagem" judaico, era comemorada com festa pela família ${ }^{57}$, porém implicava o fato de que os circuncidados ficavam sem voz ou direito de escolha, até porque eram geralmente infantes (bebês de oito dias) ${ }^{58}$

${ }^{53}$ Como lembra Paul Veyne, o sacrifício "pode reunir um grande número de significações possíveis [...] e proporciona um grande número de diversas satisfações" (VEYNE, Paul. Inviter les dieux, sacrifier, banqueter: quelques nuances de la religiosité gréco-romaine. Annales. Histoire, Sciences Sociales, année 55, n. 1, p. 3-42, janvier-février 2000. p. 21), dentre as quais a substituição que, segundo Parker, "só é relevante em relação a uma gama restrita de sacrifícios" (PARKER, Robert. Substitution in Greek Sacrifice. In: BONNECHERE, Pierre; GAGNÉ, Renaud (ed.). Sacrifices humains: Perspectives croisées et representations/Human Sacrifice: Cross-cultural perspectives and representations. Liège: Presses Universitaires de Liège, 2013. p. 145-152 [152]).

${ }^{54}$ Em geral, as práticas ritualísticas nas quais um indivíduo substitui o coletivo são denominadas pelo termo "bode expiatório", como meio de generalização das mesmas. Apesar do bode expiatório judaico (Lv 16) ser de fato um bode, há casos em outras culturas em que o "bode expiatório" é um ser humano, a exemplo do pharmakós ( $\varphi \alpha \rho \mu \alpha \chi o ́ \varsigma)$ grego, que era uma pessoa designada para servir de meio de expiação de todo o coletivo, ou seja, o indivíduo que sofreria (expulsão, violência etc.) para purificar a cidade. Sobre os rituais de "bode expiatório" na Grécia Antiga, cf. BREMMER, Jan. Scapegoats Rituals in Ancient Greece. Harvard Studies in Classical Philology, v. 87, p. 299-320, 1983.

${ }^{55} \mathrm{O}$ caráter sacrificial da circuncisão fica explícito nas interpretações que ressaltam o efeito salvífico do sangue derramado nessa, a exemplo do Targum Onkelos. Cf. WILLIS, 2010, p. 18; GLICK, 2006, p. 2027; GLICK, Nansi S. Zipporah and the Bridegroom of blood. In: DENNISTON, George C. et al. (ed.). Bodily Integrity and the Politics of Circumcision: Culture, Controversy and Change. New York: Springer, 2006. p. 37-47 [41-43].

${ }^{56}$ O etnógrafo grego Hecateu de Abdera, por exemplo, não menciona a circuncisão quando fala dos costumes judaicos. Possivelmente isso decorre do fato de que "nem ele nem seus leitores tomavam a circuncisão como peculiarmente judaica” (Bar-Kochva, 2010, p. 115). Havia, na verdade, uma identificação dessa prática com os egípcios, resultante da ampla leitura de Heródoto, e ganha ainda mais força pela conservação da mesma na obra de Hecateu (Diod. Sic., Bib. Hist., 28.1-3).

57 “Especialmente os 'ritos de passagem' (circuncisão, casamento, atos fúnebres) eram grandes eventos nas vidas dos israelitas antigos. Festejava-se uma semana inteira, com boas refeições e bebidas, música e dança" (GERSTENBERGER, 2002, p. 84).

${ }^{58}$ Cabe notar que, apesar da instituição da circuncisão para os meninos de oito dias de idade (Gn 17.12), o filho primogênito de Abraão, Ismael, que é circuncidado neste primeiro momento (Gn 17.25-26), já não era mais um bebê, mas tinha a idade de 13 anos (Gn 17.25), justamente a idade que, pela lei judaica, o

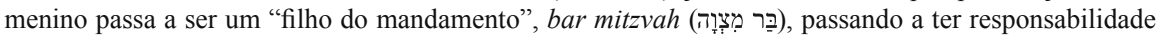


ou escravos. Assim, é o próprio Abraão quem circuncida seu filho e seus escravos, enquanto sua decisão, pelo que Deus havia lhe falado:

Tomou, pois, Abraão a seu filho Ismael, e a todos os escravos nascidos em sua casa, e a todos os comprados por seu dinheiro, todo macho dentre os de sua casa, e lhes circuncidou a carne [bāsār] do prepúcio de cada um, naquele mesmo dia, como Deus lhe ordenara ${ }^{59}$.

Apesar da circuncisão se expressar como imposição de Abraão sobre seu filho e escravos, para o próprio Abraão foi uma decisão. Sua circuncisão ${ }^{60}$, portanto, diferente da circuncisão dos demais, pois foi uma escolha de alguém sobre seu próprio corpo, apesar do aspecto impositivo do requerimento divino. Além do patriarca Abraão, ainda outros homens tiveram a circuncisão enquanto uma decisão e não uma imposição decorrente do controle familiar: com o surgimento dos prosélitos ${ }^{61}$, por exemplo, esses também decidiam a respeito de sua circuncisão. Alguém poderia, portanto, escolher pertencer ao judaísmo mediante a adoção da circuncisão. ${ }^{62}$ Porém, a circuncisão também se deu como decisão nas situações de proibição da mesma, apesar de ser uma decisão dos pais, e não das próprias crianças circuncidadas. Tratava-se de uma decisão sobre o outro, mas também sobre si mesmo, pelas consequências que poderiam sofrer por praticarem a circuncisão.

Quando o rei selêucida Antíoco IV, chamado Epifânio, estabeleceu uma nova constituição para os judeus, esses se viram em uma situação de proibição de práticas tradicionais do judaísmo, a exemplo do sábado, das leis kosher e mesmo da circuncisão. Os livros de 1 Macabeus e 2 Macabeus, que tratam a respeito dessa

sobre suas ações. Segundo William H. Propp (PROPP, 1987, p. 355, nota 1) é possível que esse relato tenha sido a base das afirmações de Josefo (Ant. Jud., 1.214) e Eusébio (Praep. Ev., 6.11.69) que os árabes praticavam a circuncisão em idade de 13 anos. De fato, porém, a circuncisão tende a ser uma prática vinculada à passagem do menino à maioridade, geralmente por volta dos 13 anos.

${ }^{59}$ Gn 17.23 (ARA), grifo nosso.

${ }^{60}$ Segundo o relato bíblico (Gn 17.24-27), Abraão é circuncidado no mesmo dia que seu filho e seus escravos, quando contava com 99 anos.

${ }^{61}$ Apesar do termo grego prosélytos ( $\left.\pi \rho \circ \sigma \eta ́ \lambda v \tau o \varsigma\right)$ ser utilizado na Septuaginta como indicação de estrangeiros, é comumente identificada como referente a um "convertido ao judaísmo", uma vez que é o significado mais forte nas inscrições a partir do primeiro século (BIRD, Michael F. Crossing over Sea and Land: Jewish Missionary Activity in the Second Temple Period. Peabody: Hendrickson, 2010. p. 40).

62 "Assim, se os gentios quisessem entrar na comunidade judaica e fazer parte do judaísmo, então teriam que passar pela circuncisão" (BIRD, 2010, p. 40). Filo, porém, fala dos prosélitos que não seriam circuncidados, cf. Filo, Quaest. Ex., 2.2. 
"perseguição" ${ }^{33}$ e a consequente Revolta dos Macabeus ${ }^{64}$ - que acabou por alcançar a independência judaica em relação ao domínio selêucida -, afirmam que algumas mulheres decidiram circuncidar seus filhos, vindo a ser mortas por causa disso (1 Mac 1.60; 2Mac 6.10), assim como outras pessoas (1Mac 1.61). A participação das mulheres na circuncisão é importante de ser destacada, pois, como ressaltou Thomas Römer, "normalmente não é permitido que uma mulher circuncide um homem" ${ }^{5}$. Além do já mencionado caso de Zípora (em Êxodo 4.24-26), também os textos de 1 Macabeus 1.60 e 2 Macabeus 6.10 destacam a participação feminina nas circuncisões. Em ambos os casos, porém, havia um contexto de perigo mortal: no relato de Êxodo o perigo da morte de Moisés (ou seu filho) se não houvesse a circuncisão, e nos casos de 1 e 2 Macabeus o perigo no caso da circuncisão ser descoberta, já que estava proibida. Nos três casos, assim como ao longo do relato do Êxodo, há, segundo Thomas Römer, uma valorização das mulheres ${ }^{66}$, que ganham destaque quando assumem os papéis que normalmente caberiam aos homens, mas para com os quais os homens estão sendo omissos. As mulheres, desta forma, ganham projeção, portanto, como símbolos de decisão e enfrentamento e, nos casos da revolta dos Macabeus, de resistência. ${ }^{67}$ A circuncisão, portanto, torna-se nesse contexto um elemento de resistência ${ }^{68}$, uma pauta presente na propaganda das leis ancestrais ${ }^{69}$, defendidas pelos partidários dos macabeus, assim como uma questão de escolha.

$\mathrm{O}$ aspecto de escolha da circuncisão se evidencia em um texto bastante singular de 1 Macabeus (1.15), onde é dito que alguns judeus "restabeleceram seus

${ }^{63}$ A proibição de vários elementos da Torá durante o reinado de Antíoco IV foi percebida pela tradição judaica (especialmente 1 Macabeus e 2 Macabeus) como uma perseguição de Antíoco ao judaísmo. Apesar de 1 e 2 Macabeus estabelecerem um relato dessa perseguição sob aspectos literários evidentes e mediante uma construção identitária clara, como bem demonstrou Steven Weitzman (WEITZMAN, Steven. Plotting Antiochus's Persecution. Journal of Biblical Literature, v. 123, n. 2, p. 219-234, 2004), isso não impede que de fato tenha ocorrido dessa forma, como uma perseguição de Antíoco aos judeus, seja por questões religiosas (Jonathan Goldstein), políticas (Klaus Bringmann), pessoais (Erich S. Gruen), ou mesmo por ignorância quanto às consequências (Robert Doran). Cf. DORAN, Robert. The Persecution of Judeans by Antiochus IV: The Significance of 'Ancestral Laws'. In: HARLOW, Daniel C. et al. The "Other" in Second Temple Judaism: Essays in Honor of John J. Collins. Grand Rapids: Eerdmans, 2011. p. 423-433.

${ }^{64}$ Segundo Victor Tcherikover, deve-se ver a ordem contrária: "Não é a revolta que veio como resposta à perseguição, mas a perseguição que veio como uma resposta à revolta" (TCHERIKOVER, Victor. Hellenistic Civilization and the Jews. Philadelphia; Jerusalem: The Jewish Publication Society of America; The Magness Press; The Hebrew University, 1959. p. 191).

${ }_{65}^{6}$ RÖMER, Thomas. Moses and the women in Exodus 1-4. Indian Theological Studies, v. 52, n. 3, p. $237-$ 250, Sept. 2015. p. 249.

${ }^{66}$ Thomas Römer destacou que os textos de Êxodo 1.15-22, 2.1-10 e 4.24-26 "demonstram que as mulheres desempenharam uma parte importante na libertação de Israel do Egito” (RÖMER, 2015, p. 250).

${ }^{67}$ Outra figura feminina importante como símbolo de resistência em 2 Macabeus é a mãe martirizada com seus sete filhos, em 2 Macabeus 7. Essa mulher, não nomeada em 2 Macabeus, é usualmente identificada como Hannah (Ana), estando referenciada até mesmo no Talmude (Gittin 57b).

${ }^{68}$ Michael F. Bird lembra que a circuncisão se tornou "um símbolo de resistência nacional ao helenismo" (BIRD, 2010, p. 25) e traz as seguintes referências: 1Mac 1.48,60; 2Mac 6.10; Josefo, Cont. Ap., 1.171; Ant. Jud., 1.192-193,214.

${ }^{69}$ Cf. DORAN, 2011. 
prepúcios"70. Não fica claro, aqui, se é uma imagem metafórica ${ }^{71}$ a fim de evocar a escolha de alguns judeus pelo modo de vida helênico ${ }^{72}$, ou se de fato é uma referência ao processo de epispasmos, uma operação para se restituir o prepúcio. ${ }^{73}$ De toda forma, é bem possível que, se no ginásio grego construído por Jasão em Jerusalém, os atletas tenham participado pelados ${ }^{74}$, a circuncisão tenha se tornado um mecanismo de diferenciação explícita. Independentemente da literalidade da questão, porém, a circuncisão ganha, nesse contexto, um aspecto de decisão, tornando-se propriamente em um símbolo de resistência, e "a marca essencial da identidade israelita"75. Essa marca, apesar de ter se tornado em uma forma de imposição durante a dinastia dos asmoneus, que veio ao poder após a Revolta dos Macabeus, uma vez que esses obrigaram povos vizinhos conquistados a praticar a circuncisão ${ }^{76}$, permaneceu como elemento principalmente vinculado à resistência judaica, sendo uma das principais causas de importantes revoltas, a exemplo da Revolta de Bar Kokhba.

Apesar de 2 Macabeus apresentar Jasão e outros judeus helenizados como verdadeiros traidores do "judaísmo"77, por não seguirem a tradição judaica, mas antes viverem em grande medida pelos valores helênicos, 2 Macabeus constitui-se sobre uma polarização bastante artificial. O que ficou compreendido como uma "negação" e ainda "perseguição" ao judaísmo poderia ainda ser visto como uma tentativa de reforma da religião e cultura judaicas por parte de judeus helenizados que teriam outra

70 Seguimos aqui a tradução da Bíblia de Jerusalém.

${ }^{71}$ Robert Doran, por exemplo, defende essa perspectiva. Cf. DORAN, Robert. Jason's Gymnasion. In: ATTRIDGE, Harold W.; COLLINS, John J.; TOBIN, Thomas M. (eds.). Of scribes and scrolls: studies on the Hebrew Bible, intertestamental Judaism, and Christian origins presented to John Strugnell on the occasion of his sixtieth birthday. Lanham: University Press of America, 1990. p. 99-109 [108]. O uso de algumas imagens metafóricas evidentes, como o pétaso (2Mac 4.12), e o disco (2Mac 4.14), parecem fortalecer essa perspectiva.

72 Segundo Martha Himmelfarb, no livro de 2 Macabeus não são os gregos os "inimigos”, mas antes "o modo de vida grego é o inimigo" (HIMMELFARB, Martha. Judaism and Hellenism in 2 Maccabees. Poetics Today, v. 19, n. 1, p. 19-40, 1998. p. 29). Trata-se de um inimigo por ser "uma ameaça aos valores tradicionais" (HIMMELFARB, 1998, p. 28), pois promove uma "inovação perigosa” (HIMMELFARB, 1998, p. 27). De fato, há uma verdadeira oposição entre helenismo (hellenismos) e judaísmo (ioudaismos) em 2 Macabeus. Sobre o assunto, cf. HIMMELFARB, 1998.

${ }^{73}$ Quem passava por tal operação de reconstituição do prepúcio era chamado pelos gregos de epispastikós e pelos romanos de recutitio e, segundo o médico Celso, poderiam alcançar essa reconstituição por meio de duas formas de operação (cf. Aulus Cornelius Celsus, De medicina libri octo, 7.25). Sobre a questão, cf. SCHULTEISS, Dirk et al. Uncircumcision: A Historical Review of Preputial Restoration. Plastic and Reconstructive Surgery, v. 101, n. 7, p. 1.990-1.998, June 1998; HALL, R. G. Epispasm: circumcision in reverse. Bible Review, p. 52-57, August 1992; 1 Coríntios 7.18; Testamento de Moisés 8.3.

${ }^{74}$ Robert Doran questiona essa perspectiva, lembrando que a nudez não era um aspecto obrigatório de todos os ginásios, de modo que muitos boxeadores em diversas partes lutavam cobertos (cf. Tucídides, Hist., 1.6), assim como que o autor de 2 Macabeus teria mencionado o fato da nudez no ginásio, se fosse dessa forma. Cf. DORAN, 1990, p. 106.

${ }^{75}$ COHEN, Shaye J. D. From the Maccabees to the Mishnah. 2. ed. Louisville: Westminster John Knox, 2006. p. 43-44.

${ }^{76}$ Cf. DABROWA, Edward. The Hasmoneans and the Religious Homogeneity of their State. Scripta Judaica Cracoviensia, Krákow, v. 8, p. 7-14, 2010.

77 Cabe destacar que o termo "judaísmo" (ioudaismos) aparece pela primeira vez em 2 Macabeus, de modo que parece ter sido inventado pelo autor desse livro (HIMMELFARB, 1998, p. 20). 
percepção sobre o que é judaísmo. ${ }^{78}$ Assim, ao mesmo tempo em que a circuncisão se caracterizou nesse contexto enquanto uma forma de decisão, tornou-se ainda uma imposição de alguns judeus sobre outros, da parte de um segmento do grupo sobre outro. Desta forma, não só Abraão sofreu violência pelo discurso divino ${ }^{79}$, como ainda os judeus helenizantes sofreram violência indiretamente por esse discurso - o discurso religioso exerceu ao mesmo tempo independência e violência sobre os fiéis, sendo um símbolo ambivalente de decisão, resistência e imposição.

A imposição exercida pelos asmoneus, já mencionada, encontra um paralelo bíblico no texto de Gênesis 34: após o heveu Siquém tomar Diná, filha de Jacó, para si, os filhos de Jacó lhe fazem uma oferta para que ambos povos - judeus e heveus - pudessem conviver: "Sob uma única condição permitiremos: que vos torneis como nós, circuncidando-se todo macho entre vós" (Gn 34.15). Sob a aceitação dessa condição, há a promessa, feita pelos judeus, que estes e os heveus viriam a se tornar um só povo (Gn 34.16,22), mas, mesmo tendo estes últimos se circuncidado (Gn 34.24), foram mortos por Simeão e Levi (Gn 34.25), traiçoeiramente, enquanto sofriam pela operação. Ainda outra história, uma anedota relatada no Talmude, traz a circuncisão como condição irrevogável para unificação dos povos: "César disse ao R. Tanhum: 'Vamos, tornemo-nos todos um povo'. R. Tanhum respondeu: 'Muito bem! Nós que somos circuncidados não podemos ser como vocês. ${ }^{80}$ Vocês se circuncidem e sejam como nós"” (B. Sanhedrin 39a). Em ambos os casos - Gênesis 34 e no Talmude -, além do caráter irrevogável da circuncisão, pode-se perceber um elemento mais sutil, que subjaz a ambos relatos: o desejo da diferença.

\section{Considerações finais}

Pertença, violência e resistência - esses três elementos são constituidores de diferença, diferenciando ao mesmo tempo que ligando os indivíduos. Essa é uma marca própria da doutrina, dentro da qual a circuncisão se insere, uma vez que, como bem indicado por Michel Foucault, ao mesmo tempo em que a doutrina proíbe todos os outros tipos de enunciação, também "se serve, em contrapartida, de certos tipos

${ }^{78} \mathrm{O}$ primeiro a desenvolver consideravelmente essa perspectiva foi Elias J. Bickerman, que viu na Revolta dos Macabeus, "uma guerra civil, uma luta religiosa entre reformistas e ortodoxos" (BICKERMAN, Elias. Studies in Jewish and Christian History: a new edition in english including The God of the Maccabees. 2 v. Edited by Amram Tropper. Leiden; Boston: Brill, 2007. p. 1.125 [II]). Essa ideia foi seguida por Martin Hengel, e mais recentemente por JoAnn Scurlock (SCURLOCK, JoAnn. 167 BCE: Hellenism or Reform? Journal for the Study of Judaism, v. 31, n. 2, p. 125-161, 2000).

79 A ordem divina "todo macho entre vós será circuncidado" (Gn 17.10b, ARA) ou ainda "circuncidareis a carne do vosso prepúcio" (Gn 17.11a,ARA) não é somente impositiva por ter um sentido imperativo, mas ainda pela consequência negativa sujeita ao seu descumprimento: "O incircunciso, que não for circuncidado na carne do vosso prepúcio, essa vida será eliminada do seu povo; quebrou a minha aliança” (Gn 17.14, ARA). Nesta passagem, a Septuaginta e o Pentateuco Samaritano acrescentam "no oitavo dia", indicando a desobediência caso essa data não fosse cumprida. Cf. Jubileus 15.14,26. A expressão "eliminada do seu povo" (17.14) possivelmente se referia ao fim da linhagem de uma família. Cf. PROPP, 1987, p. 356, nota 7.

${ }_{80}$ Parece carregar consigo a ideia da impossibilidade prática da restituição do prepúcio, o que, conforme já explicado, era possível já na antiguidade. 
de enunciação para ligar indivíduos entre si e diferenciá-los, por isso mesmo, de todos os outros" "1. A pertença a um grupo implica a diferença, implica não ser como todos, senão como especificamente aqueles que formam o grupo. É por isso que a circuncisão, como marca intencional de diferença, tendeu a servir como elemento de distinção e afastamento, tanto de quem era circuncidado como ainda de quem não era, tal como indicou Sigmund Freud: "Os que o não adotaram consideraram-no demasiado estranho e horrível; os que praticaram a circuncisão sentiram-se orgulhosos com isso, como que enobrecidos, e desprezaram os incircuncisos, que classificaram de impuros" $" 2$.

Nos jogos de relações de força, a circuncisão moveu-se como um pêndulo, como forma de resistência às imposições externas de gregos e romanos, ao mesmo tempo em que voltava a impor-se como doutrina. Elemento unificador, a circuncisão integra família, sociedade e cultura, assim como marca e define uma identidade, ao mesmo tempo em que é um elemento de quebra, separação e corte - um corte físico e íntimo que marca a criança e lhe impõe um espaço, um grupo e uma história.

É a história da circuncisão, presente no texto bíblico, mas ultrapassando-o, que explicita a importância polivalente dessa prática, assim como sua importância como símbolo da diferença. Mas esse aspecto, como símbolo da diferença, está presente nas bases bíblicas da mesma, afinal, se a circuncisão é o símbolo da aliança com Deus, é porque Deus escolheu um povo - e somente um povo - para ser o seu povo. Se a aliança fosse para com todos, não haveria pertença, resistência ou necessidade de violência, e ainda, o mais importante - não haveria diferença. Essa diferença ainda se faz presente para com os de dentro do judaísmo, marcando oposição entre os homens, que carregam consigo o símbolo da aliança, e as mulheres, que não têm essa possibilidade, tornando-se participantes, mas não necessariamente detentoras da aliança divina. ${ }^{83}$

\section{Referências}

ANTONELLI, Judith S. In the Image of God: A Feminist Commentary on the Torah. Lanham: Rowman \& Littlefield, 2004.

BERNAT, David A. Sign of the Covenant: Circumcision in the Priestly Tradition. Atlanta: Society of Biblical Literature, 2009.

${ }^{81}$ FOUCAULT, Michel. $A$ ordem do discurso: aula inaugural no Collège de France, pronunciada em 2 de dezembro de 1970. São Paulo: Loyola, 2014. p. 41.

${ }^{82}$ FREUD, 1990, p. 47.

${ }^{83}$ Segundo Howard Eilberg-Schwartz, a diferenciação entre homem e mulher está no cerne do próprio sentido da circuncisão: "Circuncisão é um ritual pós-parto associado à separação de um filho homem de sua mãe. Quando a criança é removida da impureza do sangue de sua mãe, é trazido à aliança pela aspersão de sangue masculino. Seu sangue é limpo, unificante e simbólico da aliança de Deus. O [sangue] da sua mãe é sujo, imundo, socialmente corrompido e contaminante" (EILBERG-SCHWARTZ, Howard. Why not the earlobe? Moment, v. 17, n. 1, p. 28-33, feb. 1992. p. 32-33). Contra essa percepção, Judith S. Antonelli afirma que na realidade as mulheres não passam pela circuncisão justamente porque são tidas como "já circuncidadas", podendo participar da Páscoa (Êxx 12.48). Segundo Antonelli, a circuncisão serviria justamente como uma forma de levar o menino à posição de mulher (ANTONELLI, Judith S. In the Image of God: A Feminist Commentary on the Torah. Lanham: Rowman \& Littlefield, 2004. p. 271). 
BICKERMAN, Elias. Studies in Jewish and Christian History: a new edition in english including The God of the Maccabees. 2 v. Edited by Amram Tropper. Leiden; Boston: Brill, 2007.

BÍBLIA SAGRADA. Traduzida em Português por João Ferreira de Almeida. Revista e Atualizada no Brasil. 2. ed. Barueri, SP: Sociedade Bíblica do Brasil, 2009.

BIRD, Michael F. Crossing over Sea and Land: Jewish Missionary Activity in the Second Temple Period. Peabody: Hendrickson, 2010.

BREMMER, Jan. Scapegoats Rituals in Ancient Greece. Harvard Studies in Classical Philology, v. 87, p. 299-320, 1983.

BROWN, F.; DRIVER, S. R.; BRIGGS, C. A. (eds.). A Hebrew and English Lexicon of the Old Testament: with an appendix containing the biblical aramaic. Based on the Lexicon of William Genesius as translated by Edward Robinson. Boston; New York: Houghton Mifflin Company, 1907.

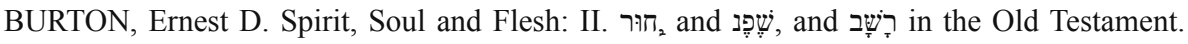
American Journal of Theology, v. 18, n. 1, p. 59-80, jan. 1914.

COHEN, Shaye J. D. From the Maccabees to the Mishnah. 2. ed. Louisville: Westminster John Knox, 2006.

DABROWA, Edward. The Hasmoneans and the Religious Homogeneity of their State. Scripta Judaica Cracoviensia, Krákow, v. 8, p. 7-14, 2010.

DORAN, Robert. Jason's Gymnasion. In: ATTRIDGE, Harold W.; COLLINS, John J.; TOBIN, Thomas M. (eds.). Of scribes and scrolls: studies on the Hebrew Bible, intertestamental Judaism, and Christian origins presented to John Strugnell on the occasion of his sixtieth birthday. Lanham: University Press of America, 1990. p. 99-109.

DORAN, Robert. The Persecution of Judeans by Antiochus IV: The Significance of 'Ancestral Laws'. In: HARLOW, Daniel C. et al. The “Other” in Second Temple Judaism: Essays in Honor of John J. Collins. Grand Rapids: Eerdmans, 2011. p. 423-433.

EILBERG-SCHWARTZ, Howard. The Savage in Judaism: An Anthropology of Israelite Religion and Ancient Judaism. Bloomington: Indiana University Press, 1990.

EILBERG-SCHWARTZ, Howard. Why not the earlobe? Moment, v. 17, n. 1, p. 28-33, feb. 1992. FOUCAULT, Michel. A ordem do discurso: aula inaugural no Collège de France, pronunciada em 2 de dezembro de 1970. São Paulo: Loyola, 2014.

FREUD, Sigmund. Moisés e a religião monoteísta. Tradução Paulo Samuel. Lisboa: Guimarães, 1990.

GERSTENBERGER, Erhard. Casa e casamento no Antigo Testamento. Estudos Teológicos, v. 42, n. 1, p. 81-89, 2002.

GIRARD, René. A violência e o sagrado. 3. ed. São Paulo: Paz e Terra, 2008.

GLICK, Leonard B. The Life of the Flesh is in the Blood: The Meaning of Bloodshed in Ritual Circumcision. In: DENNISTON, George C. et al. (ed.). Bodily Integrity and the Politics of Circumcision: Culture, Controversy and Change. New York: Springer, 2006. p. 17-36.

GLICK, Nansi S. Zipporah and the Bridegroom of blood. In: DENNISTON, George C. et al. (ed.). Bodily Integrity and the Politics of Circumcision: Culture, Controversy and Change. New York: Springer, 2006. p. 37-47.

GOLDBERG, Louis. Bayit. In: HARRIS, R. Laird; ARCHER JR., Gleason L.; WALTKE, Bruce K. (eds.). Dicionário Internacional de Teologia do Antigo Testamento. São Paulo: Vida Nova, 1998. p. 174-176.

HALL, R. G. Epispasm: circumcision in reverse. Bible Review, p. 52-57, August 1992.

HERODOTUS. With an English Translation by A. D. Godley. In Four Volumes. Volume I: Books I and II. Cambridge, MA/London: Harvard University Press/William Heinemann, 1975. 
HIMMELFARB, Martha. Judaism and Hellenism in 2 Maccabees. Poetics Today, v. 19, n. 1, p. 19-40, 1998.

HODGES, Frederick Mansfield. The Ideal Prepuce in Ancient Greece and Rome: Male Genital Aesthetics and Their Relation to Lipodermos, Circumcision, Foreskin Restoration, and the Kynodesmē. Bulletin of the History of Medicine, v. 75, n. 3, p. 375-405, Fall 2001.

HOFFMAN, Lawrence A. Covenant of Blood: Circumcision and Gender in Rabbinic Judaism. Chicago; London: University of Chicago Press, 1996.

KAPLAN, Lawrence. 'And the Lord sought to kill him' (Exod 4:24): yet once again. Hebrew Annual Review, v. 5, p. 65-74, 1981.

MORAES, Reginaldo Pereira de. A família no Antigo Oriente Próximo: uma descrição veterotestamentária. Hermenêutica, v. 11, n. 1, p. 65-79, 2011.

NIEHOFF, Maren R. Circumcision as a Marker of Identity: Philo, Origen and the Rabbis on Gen 17:1-14. Jewish Studies Quarterly, v. 10, p. 89-123, 2003.

OSWALT, John N. Bâsar. In: HARRIS, R. Laird; ARCHER JR., Gleason L.; WALTKE, Bruce K. Dicionário Internacional de teologia do Antigo Testamento. São Paulo: Vida Nova, 1998. p. 226-228.

PARKER, Robert. Substitution in Greek Sacrifice. In: BONNECHERE, Pierre; GAGNÉ, Renaud. (ed.). Sacrifices humains: Perspectives croisées et representations/Human Sacrifice: Cross-cultural perspectives and representations. Liège: Presses Universitaires de Liège, 2013. p. 145-152.

PATTERSON, Cynthia. 'Not Worth the Rearing': The Causes of Infant Exposure in Ancient Greece. Transactions of the American Philological Association, v. 115, p. 103-123, 1985.

PROPP, William H. The Origins of Infant Circumcision in Israel. Hebrew Annual Review, v. 11, p. 355-370, 1987.

REISS, Moshe. Jephthah's Daughter. Jewish Bible Quarterly, v. 37, n. 1, p. 57-63, 2009. RÖMER, Thomas. Moses and the women in Exodus 1-4. Indian Theological Studies, v. 52, n. 3, p. 237-250, Sept. 2015.

RUPPENTHAL NETO, Willibaldo. A vida humana no Antigo Testamento. Protestantismo em Revista, São Leopoldo, v. 42, p. 172-185, set./dez. 2016.

RUPPENTHAL NETO, Willibaldo. O ser humano necessitado: as implicações do conceito de nefesh nas ideias de homem, vida e morte na antropologia do Antigo Testamento. Trabalho de Conclusão de Curso (Teologia) - Faculdades Batista do Paraná, Curitiba/PR, 2015.

SCHMITZ, Winfried. Exposure of children. In: BAGNALL, Roger S. et al. The Encyclopedia of Ancient History. New York: Wiley-Blackwell, 2013. p. 2.604-2.605.

SCHULTEISS, Dirk et al. Uncircumcision: A Historical Review of Preputial Restoration. Plastic and Reconstructive Surgery, v. 101, n. 7, p. 1.990-1.998, June 1998.

SCURLOCK, JoAnn. 167 BCE: Hellenism or Reform? Journal for the Study of Judaism, v. 31, n. 2, p. 125-161, 2000.

STOOP, Ben. The Sins of their Fathers: Si pater filium ter venum duit. Revue internationale des droits de l'antiquité, n. 42, p. 331-392, 1995. 
TCHERIKOVER, Victor. Hellenistic Civilization and the Jews. Philadelphia; Jerusalem: The Jewish Publication Society of America; The Magness Press; The Hebrew University, 1959.

VAILATTI, Carlos Augusto. A Torá e o Mal: um estudo sobre os demônios na Torá. Revista Vértices, n. 12, p. 152-176, 2012.

VEYNE, Paul. Inviter les dieux, sacrifier, banqueter: quelques nuances de la religiosité gréco-romaine. Annales. Histoire, Sciences Sociales, année 55, n. 1, p. 3-42, janvierfévrier 2000.

VEYNE, Paul. O Império Romano. In: VEYNE, Paul. (org.). História da Vida Privada. Volume 1: Do Império Romano ao Ano Mil. 9. reimp. São Paulo: Companhia das Letras, 1993.

VON RAD, Gerhard. Genesis: A Commentary. Louisville: Westminster John Knox Press, 1972. (Old Testament Library).

WEITZMAN, Steven. Plotting Antiochus's Persecution. Journal of Biblical Literature, v. 123, n. 2, p. 219-234, 2004.

WILLIS, John T. Yahweh and Moses in conflict: The Role of Exodus 4:24-26 in the Book of Exodus. Bern: Peter Lang, 2010.

WOLFF, Hans Walter. Antropologia do Antigo Testamento. São Paulo: Hagnos, 2008. 